\title{
COVID-19: The Rising Cost of Cardiac Surgery and Disease
}

\author{
Fatima Osman ${ }^{1}$, Noah Caplin² , and Mohamad Bashir ${ }^{3}$ \\ ${ }^{1}$ Imperial College London Faculty of Medicine \\ ${ }^{2}$ University of Oxford \\ ${ }^{3}$ Barts Health NHS Trust
}

October 24, 2020

\begin{abstract}
The coronavirus disease 19 (COVID-19) pandemic has resulted in widespread economic, health and social disruptions. The delivery of cardiovascular care has been stifled during the pandemic in order to adhere to infection control measures as a way of protecting patients and the workforce at large. This cautious approach has been protective since individuals with COVID-19 and cardiovascular disease are anticipated to have poorer outcomes and an increased risk of death. The combination of postponing elective cardiovascular surgeries, reduced acute care and long-term cardiac damage directly resulting from COVID-19 will likely have increased the demand for cardiac care, particularly from patients presenting with more severe symptoms. The combination of increased demand and inhibited supply will likely result in huge backlog of unmet patients' needs. The novelty, virulence and infectivity of severe acute respiratory syndrome coronavirus 2 (SARS-CoV-2) has caused substantial morbidity and mortality which have necessitated modifications to the UK government's healthcare strategy. Without improving cost efficiency, the UK's ageing population will likely need an increasing spend on cardiac surgery simply to maintain the same level of service. However, the government's short-term increase in spending is unsustainable especially in the face of ongoing economic uncertainty. This means that the long-term impact of COVID-19 will only increase the need to find innovative ways of delivering equivalent or superior cardiac care at a reduced unit cost.
\end{abstract}

\section{Hosted file}

COVID-19- The Rising Cost of Cardiac Surgery and Disease.pdf available at https://authorea. com/users/369893/articles/488702-covid-19-the-rising-cost-of-cardiac-surgery-and-disease 